\title{
Teaching Students to Attain Annual Transition Goals Using the Take Action Goal Attainment Lessons
}

Career Development and Transition for Exceptional Individuals 20I4, Vol. 37(2) 72-83

(C) Hammill Institute on Disabilities 2013 Reprints and permissions: sagepub.com/journalsPermissions.nav DOI: 10.1 | $77 / 2$ | 65 | 43413476544 cdtei.sagepub.com

@SAGE

\author{
Jodie D. Martin, MEd', James E. Martin, PhD', and Kimberly J. Osmani, MEd ${ }^{2}$
}

\begin{abstract}
This study used the Take Action goal attainment lesson package and assistive technology to teach nine high school students with mild to moderate disabilities to attain annual transition goals. The Take Action lessons increased students' goal attainment knowledge, and this knowledge generalized to improved Plan Organizers, and slightly increased students attaining transition goals. Added weekly teacher check-ins improved adjusting plan components that did not work and goal attainment increased. Students who took action on four or five Plan Organizer components attained the most goals, and on average, students used four weekly Plan Organizers to attain a goal. Stronger interventions need to be developed to enable more students to increase the action taken on Plan Organizer components.
\end{abstract}

\section{Keywords}

disability, transition, self-determination, assistive technology

In 1987, the Adaptability Instructional Model emerged in the transition literature as a means to teach individuals with disabilities a goal setting and adjustment process to adapt to changing school and worksite demands (D. E. Mithaug, Martin, \& Agran, 1987). Numerous self-determination projects funded by the U.S. Department of Education's Office of Special Education and Rehabilitation Services and subsequent products, such as the ChoiceMaker Curriculum (Martin \& Marshall, 1995) and the Self-Determined Learning Model of Instruction (Wehmeyer, Palmer, Agran, Mithaug, \& Martin, 2000), infused and expanded on Adaptability Instructional Model concepts to improve the transition outcomes of youth with disabilities. These projects and their resulting products contributed to self-determination becoming a major instructional focus of secondary transition education (Field, 1996; Ward, 1996; Wehmeyer \& Shogren, 2013).

A growing number of studies have demonstrated the positive impact that student self-determination skills have on student outcomes. Self-determination skills enable students with disabilities to have improved academic performance (Konrad, Fowler, Walker, Test, \& Wood, 2007), and successful postschool education, employment, and community living outcomes (Martorell, Gutierrez-Recacha, Pereda, \& Ayuso-Mateos, 2008; Test et al., 2009; Wehmeyer \& Schwartz, 1997).

Numerous self-determination definitions exist, and each defines self-determination a bit differently depending on the definition's theoretical origins. Yet, agreement exists across the field (Wehmeyer \& Shogren, 2013) that from an awareness of interests, strengths, and needs, individuals with disabilities who are self-determined set goals and take action on their plans to attain their goals. This involves developing a plan, acting on that plan, evaluating progress, and making needed adjustments if the goal was not attained (Martin \& Marshall, 1995). Clearly, goal setting and goal attainment are foundational self-determination skills. To this end, Martin, Marshall, and Maxson (1993) suggested that students with disabilities learn goal setting and attainment skills starting in late elementary school years, and opportunities to learn and practice goal attainment skills need to continue through the high school years.

To demonstrate teaching goal attainment skills using a plan, act, evaluate, and adjust process, Martin et al. (2003) taught these skills to students with emotional/behavior problems. Students used a daily planning, evaluate, and adjustment organizer-like contract to set daily academic goals, schedule when they would work on their academic

\footnotetext{
'The University of Oklahoma, Norman, USA

${ }^{2}$ Oklahoma Department of Rehabilitation Services, USA
}

\section{Corresponding Author:}

Jodie D. Martin, University of Oklahoma,

Zarrow Center for Learning Enrichment,

338 Cate Center Drive, Room 190, Norman, OK, 73019, USA.

Email: jodie.martin@ou.edu 
tasks, determine the quantity and quality of what they would do, evaluate progress, and then make adjustments for the next day's plan. The results indicated the use of the organizers resulted in statistically significant increases in the goal attainment processes along with very large effect sizes, which indicate the usefulness of using the daily selfdetermination organizer-contracts to attain academic goals. The findings suggest that as adjustments improved, students became more persistent in working to attain their goals. This process verified D. K. Mithaug and Mithaug's (2003) statement that "to increase self-engagement and learning, give students a choice about their learning goals, and then give them a method for regulating their expectations, choices, actions, and results to meet those goals" (p. 142).

Field, Martin, Miller, Ward, and Wehmeyer (1998) suggested that to become self-determined, students with disabilities need opportunities to learn and practice strategies to attain their annual transition goals. Yet, Wehmeyer and Schwartz (1998) found that secondary Individualized Education Programs (IEPs) contained no goal setting and attainment annual goals. A review of the self-determination research a few years later revealed little information on how to teach the complex self-determination skills, such as goal attainment (Algozzine, Browder, Karvonen, Test, \& Wood, 2001). However, 7 years later, a survey of high school transition education practices suggests a change in special education practices had taken place. Agran and Hughes (2008) found that $70 \%$ to $80 \%$ of junior and senior high school students with IEPs had been taught to set goals, but they provided no information about students being taught to attain their goals.

Simply learning to set goals is not sufficient, as students need to actually attain their transition goals to gain benefits, and benefits do accrue for students with disabilities who learn to attain their annual transition goals. Lehmann, Bassett, Sands, Spencer, and Gliner (1999) found that two factors predicted student engagement at their transition planning meetings: (a) opportunities at school for students to learn to attain their goals, and (b) students' goal attainment skills. Benz, Yovanoff, and Doren (1997) discovered that students who attained four or more of their transition goals were more likely to be employed or enrolled in postsecondary education than students who did not attain their transition goals. Goff, Martin, and Thomas (2007) found that high school students who were Black and at high risk of dropping out of school were able to overcome the burden of "acting white" by setting and working toward attaining their postschool transition goals. Doren, Lindstrom, Zane, and Johnson (2007) interviewed numerous youth and found those who were most successful had, among other proactive factors, clear goals and they actively worked to attain them. McConnell et al. (in press) found in a review of the transition literature that former high school students with disabilities who were employed or enrolled in postsecondary educational programs set long-term goals, broke them down into smaller short-term goals, then focused on attaining goals by developing a plan and acting on that plan.

A small number of studies have examined the effectiveness of two methods to teach students with disabilities to attain their transition goals. One group of studies focused on teaching students to utilize support people to attain their goals. Balcazar, Keys, and Garate-Serafini (1995) taught six youth with emotional, behavioral, and learning disabilities living in a residential treatment school to attain transition goals. They first received brief instruction in identifying strengths and challenges, setting goals, and developing a plan of action with a strong emphasis upon identifying helpers. Next, they received instruction on how to identify and use support people to attain their goals. Role-played situations suggest students learned how to recruit and use helpers to attain goals, and students self-reported that $65 \%$ of their goals were attained. Taylor-Ritzler et al. (2001) examined the effectiveness of an intervention to enable students to establish mediated transition goals. Students set transition goals and learned how to ask for help to attain the goal. As a result, many of the students sought goal attainment support from people in their environments, and most used their support to attain at least one transition goal.

The second group of studies used strategies inspired by the Adaptability Instruction Model (D. E. Mithaug et al., 1987). This approach utilized a comprehensive set of selfmanagement skills, including goal setting, planning, selfevaluation, and adjustments to improve students' goal attainment. German, Martin, Marshall, and Sale (2000) used a goal attainment lesson package titled "Take Action: Making Goals Happen" (Marshall et al., 1999) to teach high school students with intellectual disabilities. Students learned the plan, act, evaluate, and adjust sequence and applied these concepts using graphic organizers to attain their daily transition goals, and then maintained these new goal attainment skills after instruction concluded. Finn, Getzel, and McManus (2008) used a modified version of the Self-Determined Learning Model of Instruction (Wehmeyer et al., 2000) to teach college students with disabilities to set a goal, take action on the goal by detailing a plan for attaining the goal, and adjusting the goal and plan as needed to achieve success. All participants reported positive changes in their goal setting and attainment skills and about a third of these reported significant improvement in setting and attainting their goals.

Clearly, more research is needed to enable student attainment of annual transition goals to become a valued and effective transition education practice. Thus, the purpose of this study was to determine (a) whether the Take Action goal attainment instructional program could teach essential goal attainment knowledge to students with mild to moderate disabilities, (b) whether increased goal attainment knowledge would increase students use of goal 
attainment skills, and (c) whether students' use of goal attainment skills would increase their attainment of shortterm transition goals.

\section{Method}

\section{Participant Selection}

Special education directors from school districts across a Southwestern state were invited to become involved in this goal attainment transition education project, and interested districts submitted application packets, which included school information, student demographics, and school records. A committee comprised of representatives from the Department of Rehabilitation Services, a state-sponsored assistive technology center, and a university research center reviewed the files. After examining the files, two school sites, which we titled "Central High School" and "Will Rogers High School," were selected, and additional recruitment of students at these schools yielded nine students who completed the entire study.

Student participants. The study included nine students, five of whom were male. Eight of the students were Caucasian, and one was African American. Three of the students had a specific learning disorder, three had autism, two had emotional/ behavioral disorders, and one had an intellectual disability.

These 10th- and 11th-grade students with IEPs spent at least one class period per day in a study skills classroom setting, and most spent the rest of their school day included in general education classes. According to the special education teachers, students had the reading and writing skills to participate in this goal attainment project. Two students attended Will Rogers High School and seven went to Central High School.

Teacher participants. Two female special education teachers volunteered to provide instruction to the student participants. Both teachers were certified to teach special education and had taught students with disabilities for at least 20 years. Each was Caucasian, had a master's degree, and one teacher reported completing classes in transition education during her graduate studies. Each teacher received a personal copy of the Take Action lesson package for participating in the study.

\section{Setting}

The two teachers and nine students with IEPs who participated in this study came from two high schools in two school districts located in the same Southwestern state. The first school, Central High School, was located in the central part of the state, and had 1,150 ninth- through twelfth-grade students. The school made satisfactory Adequate Yearly
Progress (AYP) for the previous school year. The second school, Will Rogers High School, was located in the northeast section of the state. This school had 1,200 eleventh- and twelfth-grade students. The school had not made satisfactory AYP for the previous school year and thus students seldom left the instructional setting for nonacademic pursuits as the school increased academic instruction time to increase student academic levels. This is why students at Will Rogers High School met to participate in goal attainment instruction after school ended and not during the regular school day. Students at Central High School completed the tasks for this study during their regular school day. Instruction took place within the study skills/ resource classrooms at both high schools.

At Central High School, students received Take Action instruction for 45 min once a week for 7 weeks as part of a 90-min career-oriented technology class. During the instructional phase, students sat at their desks and completed the written components of the lessons. At Will Rogers High School, students received Take Action instruction for $1 \mathrm{hr}$ after school 1 day each week. Students sat at desks facing the front of the classroom.

\section{Design}

According to Baer, Wolf, and Risley (1968), a good design does not need to be "initiated from a textbook," but needs to answer the research question concisely (p. 319). To answer the research questions posed in this study, we used an Adapted Alternating Treatment design with an embedded $\mathrm{ABC}$ design to examine goal attainment knowledge gain, usage of goal attainment skills, and goal attainment across time (Gast, 2010). The repeated lesson pretest/ posttest delivered in an alternating fashion demonstrated knowledge gain while controlling threats to internal validity. In the ABC design, Phase A consisted of the preinstructional baseline. During Phase B, students received Take Action instruction and used Plan, Evaluate, and Adjustment Organizers to create and evaluate their plans to demonstrate the extent acquired goal attainment knowledge generalized to efforts to attain short-term annual transition goals. During Phase C, teachers provided support and feedback as students used the organizers to create, evaluate, and modify their plans to attain transition goals.

\section{Goal Attainment Lesson Materials}

The "Take Action: Making Goals Happen" instructional package (Marshall et al., 1999) teaches students how to make a plan to attain their goals. Students break their longterm goals into short-term goals, develop a six-component plan to attain their goal, and after acting on their goals, evaluate their action, and either adjust their plan or make a plan to attain the next short-term goal. 
Table I. Take Action Plan Organizer Components, the Prompting Questions, and Sample Responses.

\begin{tabular}{|c|c|c|}
\hline Component & Question prompt & Sample responses \\
\hline Short-term goal & $\begin{array}{l}\text { What is one thing I need to do to reach my } \\
\text { long-term goal this week? }\end{array}$ & Exercise regularly \\
\hline Standard & What will I be satisfied with? & Exercise 4 times this week \\
\hline Motivation & Why do I want to do this? & To make the football team \\
\hline Strategy & How will I do this? & Arrive at weight room by 7 a.m. four mornings this week \\
\hline Schedule & When will I do this? & Monday through Thursday \\
\hline Support & What help do I need? & Someone to spot my weights \\
\hline Feedback & How will I get information on my performance? & Look at my daily exercise chart that coach prepares for me \\
\hline
\end{tabular}

Plan components. The Plan Organizers prompted students to answer specific questions to develop each component of their plans. The questions were printed at the top of each plan component writing space. Table 1 lists the Plan Organizer components, and the questions students needed to answer to write each plan section.

Short-term goal. Short-term goals are smaller goals that lead students to their long-term goal. Short-term goals can be completed in a few steps in about a week. For example, if a student's long-term goal was to get in shape, a good short-term goal would be to exercise regularly.

Standard. The standard is what the student will be satisfied with doing in about 1 week. If a student is trying to get in shape, his standard would reflect how much exercise he is willing to do.

Motivation. Motivation is why the student wants to meet his standard and attain his goal. For example, a student might make a plan to get in shape so he can make the football team.

Strategy. A student's strategy is the method he will use to accomplish his goal. For a student trying to get into shape, a good strategy could be to get to the weight room early every day.

Schedule. Setting a schedule gives the student a specific time when he will work on his goal. This component also helps students find time to work on his goal when he does not have other activities planned.

Support. The support component included a list of people or things students needed to attain their goals. For example, a student who is trying to get into shape might need a stopwatch to time how long he works out, or a person to help him lift weights.

Feedback. Feedback includes any information the student receives about his progress toward attaining his short-term goal. It may include information from other people, or data collection tools the student has developed.

\section{Dependent Measures}

This study collected data on six dependent measures to answer the research questions. Because of the well-demonstrated reactive effects of self-monitoring regardless of student self-evaluation accuracy (Watson \& Tharp, 2007), we used student self-evaluation data to report five of the six dependent measures.

Percent quiz correct. Across the first six Take Action lessons, six quizzes represented the content of each lesson. During the Take Action instruction phase, we asked students to complete pretest quizzes before instruction began and posttest quizzes afterwards. The pretests and posttests were specific to the lessons and assessed student knowledge gain. New content built and expanded on the old as the lessons progressed, and in the fifth and sixth Take Action lessons, students began to use what they had learned to apply the knowledge to case studies. Because Lesson 7 represented the first individual goal attainment effort where students had to apply what they had learned, no quiz was completed with this lesson. We calculated the percent quiz correct by dividing the number of questions students answered correctly on the pretests and posttests by the number of questions on each quiz.

Percent of goals attained. Students circled "yes" or "no" on their Evaluate and Adjust Organizers to indicate if they had attained or not attained the short-term goal for which they were using their plan. We calculated percent of goals attained by dividing the number of goals attained by the number of goal plans developed, regardless of how correctly the plans were written.

Percent of action taken. Students circled "yes" or "no" on their Evaluate and Adjust Organizers to indicate whether the goal written in their plans had been attained. We divided the number of components the student reported acting on by the total number of components and multiplied by 100 to determine the percent of action taken.

Percent of no evaluations adjusted. When a student decided to keep working on the same goal or evaluated an unmet goal and decided to change it, we calculated the percent of components adjusted by dividing them by the number of 
components reported not working. For example, if the student said four components of his plan did not work, but only changed one component of the plan, we divided one by four and then multiplied that by 100 to find the percent of no evaluations the student adjusted. When a student stated all parts of his plan were effective, but he did not reach his goal, we calculated that he made zero adjustments to his plan.

Percent of plan written correctly. Students used the Plan Organizer to address each of the six components necessary for writing a plan to attain a goal. Short-term goals and plan components were accepted as correct if they provided a reasonable response to the prompt question. To calculate the percent of plan correctly written, we divided the number of plan components and short-term term goal correctly written by the total number of plan components plus the short-term goal, and then multiplied by 100 .

Percent of adjustments adopted in next plan. We calculated the percent of adjustments adopted in the next plan by dividing the number of adjustments adopted in the new plan by the number of adjustments the student said he needed to make in the previous plan. For example, if the student suggested three changes to the previous plan, but only included two of those changes in the new plan, we divided two by three and then multiplied that by 100 to find the percent of adjustments adopted in the next plan.

\section{Procedures}

Teacher instruction. Prior to beginning the study, the two cooperating teachers individually received a $1.5-\mathrm{hr}$ training on how to teach the Take Action lessons, administer the pre and posttests, schedule instruction, use the Plan Organizers, the Evaluate and Adjust Organizers, and collect demographic data. Researchers also answered any questions.

Baseline phase. Before teaching students the Take Action lesson package, we asked students to complete one Plan Organizer to describe a plan they had used in the past to attain a goal. At Central High School, seven students completed a baseline Plan Organizer before any instruction was provided. After they completed that Plan Organizer, we asked students to use the Evaluate and Adjust Organizer to assess the effectiveness of their plans. The teacher at Will Rogers did not follow the procedures for collecting baseline data, and no baseline assessment was used for the two students at that site.

Goal attainment instruction phase. To teach goal attainment, teachers followed the script included in the Take Action teacher's manual. We provided PowerPoint presentation files to guide the lessons and classroom materials needed to adequately teach the content. For Take Action Lessons 1 through 6 , the teachers had students complete the pretest, instructed on new material, and then asked students to complete the posttest. The seventh lesson had students apply what they had learned to attain a transition goal, thus no pretest or posttest was given, instead students used a Plan Organizer to develop a plan, and then used the Evaluate and Adjust Organizer to report progress on goal attainment. Pretests and posttests were derived from the Take Action curriculum and were specific to the lessons. Students who did not score $70 \%$ or higher were given followup targeted instruction to clarify their understanding. Two researchers independently scored the pretest and posttest quizzes for each lesson.

At both schools, students were asked to use the Plan Organizer to break a long-term annual transition goal they were working on into short-term goals that could be accomplished in a week, and then write a plan for one of the shortterm goals. Next, they were asked to use the Evaluate and Adjustment Organizers to assess their actions, evaluate the effectiveness of their plan, and to determine adjustments to their plan. The students were not given any instruction or feedback while they developed and used their Organizers.

Where instruction happened. At Central High School, students received Take Action instruction for 45 min once a week for 7 weeks as part of a 90-min career-oriented technology class. During the instructional phase, students sat at their desks and completed the written components of the lessons. Students looked at the teacher as she moved around the room and looked at a screen in the front of the class to see projected materials. At Will Rogers High School, students received Take Action instruction for $1 \mathrm{hr}$ after school 1 day each week. Students sat at desks facing the front of the classroom. Students looked forward at their teacher who typically stood at a podium, projected material, and discussed the lessons. This group of students had to meet after school to avoid missing any academic content instructional time due to the pressure this school faced to attain satisfactory AYP scores.

Teacher feedback on organizer phase weekly check-ins. Three weeks after goal attainment instruction ended, this phase began and students met with their teacher during a weekly check-in. Students selected a long-term transition goal and used the Plan Organizers and teacher support to break the long-term goal into weekly short-term goals that would lead to attaining the long-term goals. Students then developed with teacher support the weekly Plan Organizer. Students met each week with the teacher and used the Plan Organizers to develop a plan and then use the Evaluate and Adjust Organizers to monitor progress on attaining the short-term goals. Teachers sat with individual students to facilitate students' use of the 
Organizers and provided targeted feedback and support driven by the questions included in the Organizers.

During the Teacher Feedback on Organizer Phase weekly check-ins, the teachers asked students the component questions from the Plan Organizer and students wrote their response into the Organizer. The teachers gave feedback and support as needed to develop a complete response. After completion of the Plan Organizer, students had 1 week to act on their plans. At the end of the week, teachers met individually with students to complete the Evaluate and Adjustment Organizer. The teachers asked students whether they had acted on each component and students evaluated the action they took. Next, the teachers asked each student whether the plan components had been effective. If the student reported their action had not worked, the teacher asked what the student would change. Finally, the teacher asked the students whether they wanted to keep their short-term goals or choose another. After completing the Evaluate and Adjustment Organizers, students used the Plan Organizers to develop their next plan. The process then repeated itself week after week until the end of the spring semester when the school year ended.

\section{Instructional Fidelity}

Teachers completed a checklist at the end of each lesson during the Goal Attainment Instruction Phase to indicate whether they completed each instructional component. They marked "yes" or "no" beside each item on the lesson specific checklists. The teacher at Central High School completed checklists for five of the six instructional lessons and reported $100 \%$ instructional fidelity. The teacher at Will Rogers High School completed checklists for four of the six lessons and reported $100 \%$ fidelity to the instructional guide for those lessons.

Researchers completed an independent fidelity observation using the same checklist as the teachers and observed 12 of the 18 sessions held at both schools during the Goal Attainment Instruction Phase. Deviations from the instructor guide or other irregularities were noted. Researchers observed a $98 \%$ level of instructional fidelity. One deviation was noted, which was the failure to correctly administer the baseline organizer probe prior to instruction for the two students at Will Rogers High School.

\section{Agreement}

We used exact agreement to calculate the component-bycomponent interobserver agreement (IOA) on the written permanent products developed for each of the six dependent measures. Exact agreement was calculated by dividing the number of agreements by the total number of observations and then multiplying by 100 . Agreement across our dependent measures ranged from $93 \%$ to $100 \%$ with the following at $100 \%$ agreement: percent quiz correct, percent of goals attained, percent of action taken, and percent of adjustments adopted in next plan. The percent agreement with the percent of no evaluations adjusted was $93 \%$, and the agreement of the percent of the plan written correctly was $95 \%$.

\section{Effect Size}

Because we used percent to measure our dependent variables, we opted to create and use a variation of the Mean Baseline Reduction (MBLR) technique as the effect size measure (Campbell, 2004). The MBLR measures the overall decrease in a behavior from the baseline. The MBLR is a unique effect size indicator because it characterizes the degree of behavior change, whereas other effect size statistics, such as the percentage of zero data, characterizes the degree of behavior "suppression" (Campbell, 2004, p. 235). Our variation of the MBLR, the Mean Baseline Increase (MBLI) measured the overall increase in behavior from the baseline. We calculated the difference between the mean of the intervention data and the baseline data, dividing by the mean of the baseline data, and converting to a percent by multiplying by 100 . If the calculated effect size is positive, the behavior has increased, and if the calculated effect size is negative, the behavior has decreased.

We used the MBLI to assess the effect size of the strength of overall change in the dependent measures, as well as the strength of the change between the phases. Because no MBLR or MBLI effect size guidelines exist, we developed metrics based on the relative changes between our phases. We used the following descriptors to define the MBLI effect sizes: $<15 \%=$ slight, $16 \%$ to $59 \%=$ medium, and $>60 \%=$ large.

\section{Results}

Students set on average four to five goals, and attained average three goals. On average, students attained each goal with two to three plans, and ranged between one and nine plans. When using assistive technology (AT) as a reminder, goal attainment increased.

\section{Knowledge Quizzes}

Figure 1 depicts student responses averaged across the nine students from the two high school sites. The pre-post knowledge quizzes demonstrated that prior to instruction in the first three Take Action lessons students knew less than $50 \%$ of the goal attainment information. After instruction, the posttests indicate that students increased their knowledge, especially after the first four lessons. Much of the learned material maintained from one lesson to the next, as demonstrated by Pretests 4, 6, and 6. Student performance 


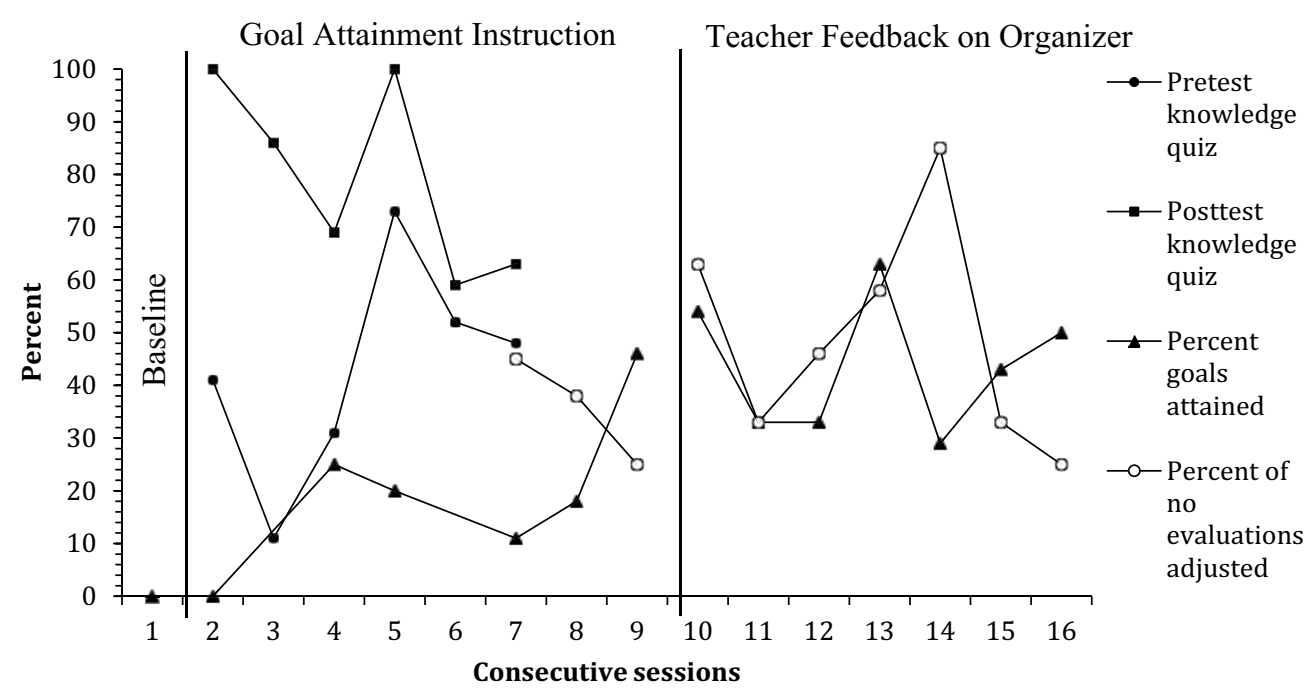

Figure I. The pre- and posttest knowledge quiz scores during the Take Action intervention demonstrated the goal attainment knowledge that students learned.

Note. The percent of adjustments to no evaluations decreased, then increased with teacher support and feedback, and may have had a strong impact on the percent of goals attained. Over time, students gradually increased the percent of goals attained and the percent of goals attained during instruction and ended the study with about half of the organizer plans resulting in attained short-term goals.

decreased during the last two quizzes as demonstrated by Posttests 6 and 6 when they were asked to apply what they had learned to case study situations.

We determined at the start of the study that if students had learned $70 \%$ or more of all the material, they had mastered the lesson package, and students attained a mean $77 \%$ posttest score. We also used a dependent samples $t$ test to determine whether the students' $77 \%$ posttest mean score significantly differed from the pretest mean of $43 \%$ at $\alpha=.05$. The posttest mean score did differ significantly from the pretest mean, $t(8)=3.705, p=.014$. Cohen's $d$ was calculated to find the instructional effect size. The effect size $d=1.91$ indicates a very large instructional effect, with .00 to $.2=$ small effect, .3 to $.5=$ moderate effect, and .6 to .8 or greater $=$ large effect.

\section{Goals Attained}

As depicted in Figure 1, students went from attaining no goals during the baseline to attaining between $30 \%$ and $60 \%$ of their short-term goals by the end of the study. Students began the Goal Attainment Instruction Phase by not attaining any goals. After gaining goal attainment knowledge and having practice in using the Plan, Evaluate, and Adjust Organizers, students gradually increased the percent of short-term goals attained from a low of $11 \%$ to $46 \%$ during the goal attainment instruction phase, with an average of $20 \%$ of the goals they set attained. Because students did not meet any goals during the baseline Phase, no MBLI was calculated.

Teacher feedback on the organizers increased and stabilized the percent of goals attained at a higher level compared with the previous instructional phase. Once teacher support was added to the weekly student check-in process, the percent of goals attained never dropped below $29 \%$, and about half of the students attained their weekly goal during four of the seven sessions. This Phase also ended with an increasing trend in the percent of goals attained.

Throughout the Teacher Feedback on Organizer Phase, the percent of goals attained varied with a strong increase of 1 week, followed by a decrease the next, but the percent of goals attained remained higher than during the initial instructional phase. Across this phase, students attained an average of $44 \%$ of the goals they set. This represents an MBLI of $118 \%$ from the previous Goal Attainment Instructional Phase, which is a large instructional effect size.

\section{Organizer Measures}

Figure 2 depicts the inner workings of the Goal Attainment and the Evaluate and Adjust Organizers across baseline, the Goal Attainment Instruction Phase, and the Teacher Feedback on Organizer Phase. These four measures depict what students did to attain their goals as measured by the organizers averaged across students at the two high schools, across time. 


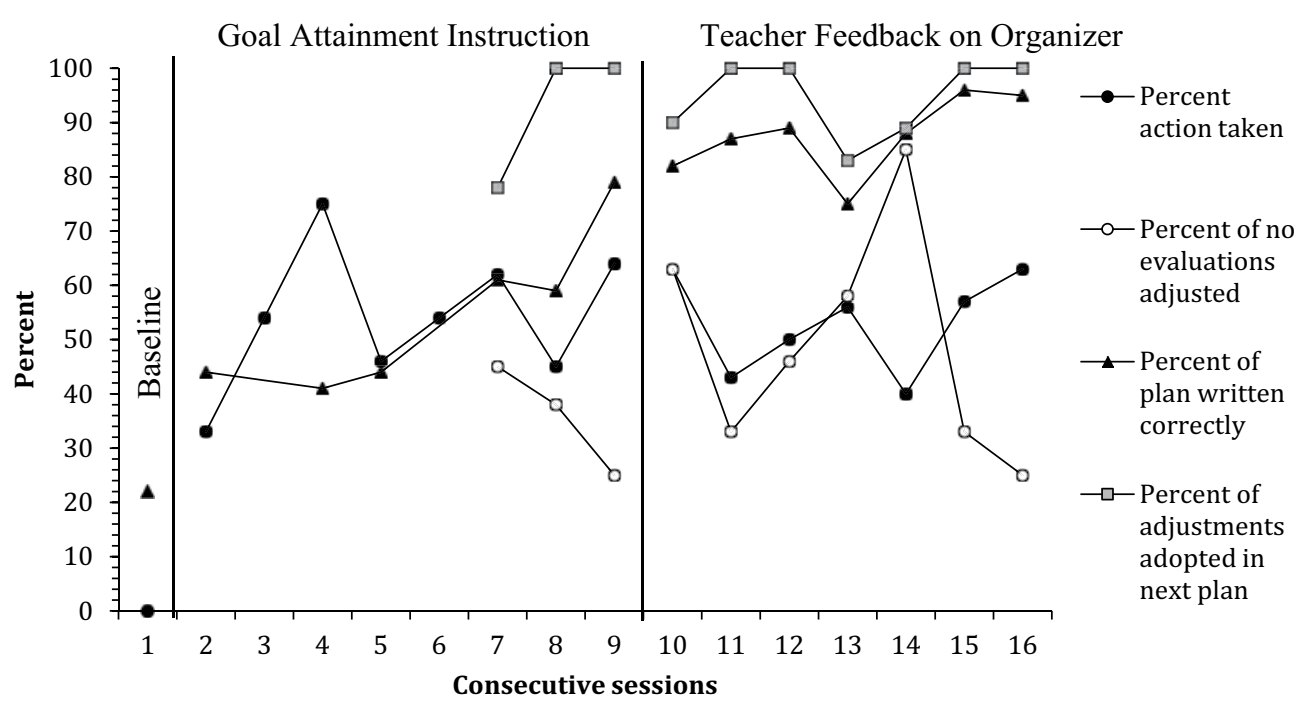

Figure 2. Across baseline, goal attainment instruction, and teacher feedback phases the various measurements of the Take Action Plan and Evaluate and Adjust Organizers are presented.

Note. By the end of the study, students correctly wrote their plans and when adjustments to the plans were made, they were almost always incorporated in the next plan. About half the time, no evaluations were adjusted and action was taken.

Percent of plans written correctly. During baseline, students wrote about $20 \%$ of their Plan Organizer correctly. Compared with baseline, a noticeable level change occurred following the first Take Action lesson in the Goal Attainment Instruction Phase, as students wrote $44 \%$ of their Plan Organizers correctly, and as students practiced writing, using, and continued learning more, the percent of Plan Organizers written correctly increased to about $80 \%$. This increase is also demonstrated in the very large $113 \%$ of plan written correctly MBLI effect size between the baseline and instructional phases. During the Teacher Feedback on Organizer Phase, the percent of Plan Organizers written correctly generally increased week after week, with $85 \%$ to $95 \%$ of the Plan Organizers written correctly during the last 3 weeks of the study. Because students were already strong in writing their goal plans at the end of the Goal Attainment Instruction Phase, a very small MBLI effect size of $4 \%$ was obtained between the Goal Attainment Instruction Phase and the Teacher Feedback on Organizer Phase.

The data suggest that during the Goal Attainment Instructional Phase, students generalized the knowledge gained from the lessons to writing their Plan Organizers. Teacher feedback and practice enabled students to continue to improve how well they wrote their plans, and this improvement maintained through the end of the study.

The percent of action taken. During baseline, students took no action on attaining their goals. Following introduction of the first Take Action lesson, the percent of action taken on the plan increased and generally followed the increasing line of progress for the percent of plan written correctly increasing to $30 \%$, then ranging between $45 \%$ and $70 \%$. Because students did not act on any plan components during the baseline phase, no MBLI can be calculated to assess the change in the percent of action they took in the next phase. Instead, it can be understood that students improved from taking no action on their plans before goal attainment instruction to acting on about $80 \%$ of the components they wrote into their plans by the end of the Goal Attainment Instruction Phase.

During the Teacher Feedback on Organizer Phase, the percent of action students took stayed between $40 \%$ and $60 \%$, which is similar to what they did during the Goal Attainment Instruction Phase. These results suggest that Teacher Feedback on the organizers had no effect on the percent of action taken on the Plan Organizers, which is evidenced by the small MBLI effect size decrease of $2 \%$ between the Goal Attainment Instruction and Teacher Feedback on Organizer Phases.

Percent of no evaluations adjusted. As depicted in Figures 1 and 2, during the Goal Attainment Instruction Phase, students first adjusted about $45 \%$ of the plan components they had evaluated as not working when this was introduced following Take Action Lesson 6. The percent of no evaluations adjusted then experienced a strong, decelerating trend, and 


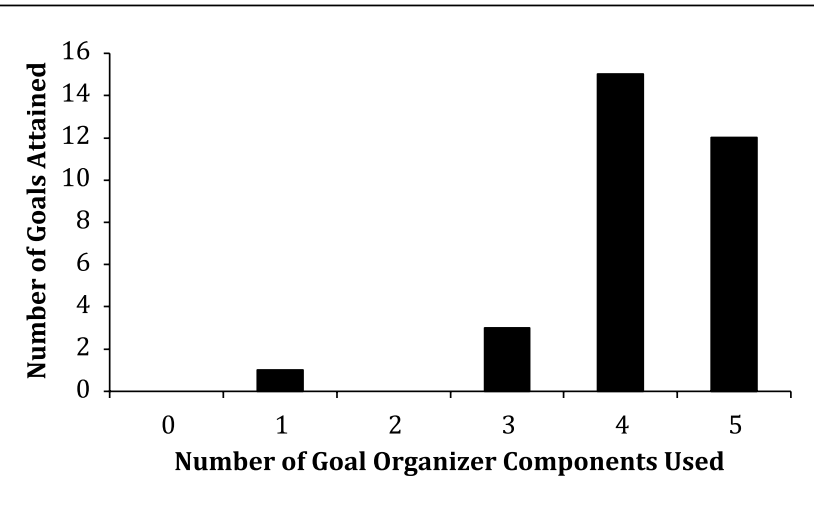

Figure 3. The number of Plan Organizer components used to attain goals since Take Action instruction ended.

Note. Because the motivation component was high and used as often if the goal was attained or not, it was excluded from this count.

by the end of the Goal Attainment Instructional Phase, students made changes to only $25 \%$ of their ineffective plan components. This sharp decrease prompted a phase change and the introduction of Teacher Feedback and Support.

The decreasing trend reversed itself in the Teacher Feedback on Organizer Phase. Students began this Phase by adjusting $63 \%$ of the plan components they had evaluated as not working, which is a strong increase from the previous phase. Across the Teacher Feedback on Organizer Phase, the percent of adjustments students made ranged from $25 \%$ to $85 \%$, with an MBLI of $36 \%$, which represents a moderate effect of the Teacher Support and Feedback intervention.

Percent of adjustments adopted in next plan. In the Goal Attainment Instructional Phase, students adjusted $80 \%$ to $100 \%$ of the plan components they had evaluated as not working after this skill was used following Take Action Lesson 6. Students began the Teacher Feedback on Organizer Phase by adopting $90 \%$ of the plan components they had adjusted. The percent of adjustments adopted in the next plan quickly increased to $100 \%$ and stayed at a high level for the remainder of the study. The results suggest that knowledge of this goal attainment skill generalized to actual practice and that students continued using this skill at a high level during the Teacher Feedback on Organizer Phase.

\section{Goal Attempted and Attained}

After Take Action Instruction ceased and until the end of the study, students chose 1 to 8 weekly transition goals, with a mean of 4.5 goals per student. To attain each goal, students used an average of 3.7 weekly Plan Organizers. Three students attained a goal with almost each organizer they used. Two students used 2 to 3 organizers to attain a goal, and two students took 8 to 9 organizers to attain 1 goal. One student never attained a goal. As depicted in Figures 1 and 2, the percent of goals attained varied from week to week, and ranged from $10 \%$ to $50 \%$ during the last 9 attempts, which reflects that on average it took students about 4 weekly organizers to attain a short-term goal.

\section{Number of Goals Attained by Number of Components Used}

Figures 1 and 2 suggest a strong relationship between the action taken on the Plan Organizers and the percent of goals attained. Figure 3 presents the number of Plan Organizer components used to attain goals across the study after the Take Action lessons ended during the Take Action Instruction Phase. Students attained the greatest number of goals when they used four or five of the Plan Organizer components. Conversely, when students used none, one, two or three of the Plan Organizer components, none to only a few goals were attained. This suggests that students need to use four or five of the goal components to attain their goals. An examination of the component use did not yield a pattern of what components yield the best outcomes if only four were used, so any of the four or five of the five Plan Organizer components (minus motivation) produced the most attained goals. Motivation was deleted because students indicated it was important whether goals were attained or not.

This relation is clearly depicted on Figures 1 and 2 in Session 9. Figure 2 shows a sharp increase in the percent of action taken during Session 9, and Figure 3 shows a corresponding increase in the percent of goals attained. This same correspondence between percent action taken and percent goals attained also exists in Sessions 10, 13, 15, and 16. Thus, the number of components used in Figure 3 match the pattern depicted in the higher percent of action taken data points depicted in Figure 2, which correspond to the percent of goal attained shown in Figure 1.

\section{Discussion}

This study sought to determine whether the Take Action goal attainment instructional program improved the goal attainment knowledge of high school students with IEPs, whether this knowledge would increase students' use of goal attainment skills, and whether the use of these skills would increase students' attainment of weekly transition goals. Results indicate that students lacked goal attainment knowledge and skills at the start of the study, and that the Take Action lesson package meaningfully and in a statistically significant manner increased students' goal attainment knowledge.

Measurement of goal attainment processes suggests that increased goal attainment knowledge improved plan writing, increased action students took on attaining goals, and increased the carry through of adjustments into the next 
plan. Increased knowledge and improvement in three basic goal attainment processes had a slight impact on actually attaining short-term transition goals. Using the organizers combined with once weekly brief teacher support and feedback check-ins on completing and using the organizers, especially on the percent of no evaluations adjusted, increased critical goal attainment skills and, as a result, goal attainment increased. On average, students used four Plan Organizers to attain each goal, with a few using one to three Plan Organizers to attain a goal. Students who used four or five of the Plan Organizer components attained the most goals compared wtih the small number students attained if they only used one or two components. Students did not attain any goals if action was not taken on any plan component.

\section{Teacher Feedback on Organizer Intervention Effect}

During the Take Action instructional phase, students had difficulty making adjustments to the components of their plan that did not work, and this troubled us because Martin et al. (2003) found that students needed to make adjustments to plan components that did not work to improve goal attainment. As a group, the students in this study often did not adjust their plans if a component in their plan did not work, and this process decreased during the last sessions of the Take Action Instruction Phase. Therefore, starting in Session 10, we implemented teacher support and feedback check-ins due to the strong decreasing trend in the percent of no evaluations adjusted. After the addition of teacher support and feedback during brief check-ins, students immediately increased the number of adjustments they made. Although the students did not reach a stable high level in making adjustments to the plan components that did not work, a positive increasing trend existed during much of the teacher feedback phase. Unfortunately, students had a sudden decrease in the percent of adjustments made to no evaluations during the last two feedback checkin sessions. During these last two sessions, the students told their teachers that they wanted the school year to end and they did not want to do any more schoolwork. Thus, we believe the approaching summer break caused students to lose focus on this project. Their classroom teachers reported that the students also lost interest in other school activities.

Students benefited greatly from having teacher support in making their plans, especially when they found themselves unable to adjust no evaluations of plan components. Yet, even with teacher support, many students kept using the same strategy to attain a goal, even if that strategy had not worked earlier. In the feedback phase, the teacher addressed this issue and advised students to mark a component "no" if it did not work, and then made suggestions about how the students could replace the nonworking plan component. When students paid attention to their "no" evaluations, they almost always followed through with a revised plan because the percent of adjustments adopted into the next plan was almost always between $90 \%$ and $100 \%$ during the teacher feedback phase. However, as the data indicate, students needed to adjust their no evaluation components more often and then take action on their new plan.

The percent of action taken generally paralleled the percent of goals attained and the percent of no evaluations adjusted. To increase the percent of goals attained, it appears from this component analysis that students needed to act on more of their plan parts, and then adjust those that did not work to increase the number of goals attained. The findings that students who acted on four or five of their Plan Organizer components attained the most goals certainly verifies this point, especially compared with the lack of goal attainment when only one or two plan components are acted upon. To increase goal attainment, more powerful interventions consisting of antecedent and consequent strategies, combined with teaching goal attainment knowledge and teacher feedback on the organizers need to be developed and implemented. This is certainly a task that future research needs to examine.

\section{Teacher Thoughts}

The teacher participants in the study found that having students develop their own plans and having the structured check-ins with students placed accountability on the students. When a student reported at a check-in that he did not work on his goal because he was not interested in it, the teachers replied that the student had selected his goal, and that if he was not interested in the goal, he needed to select a transition goal of interest and develop a plan. Students responded positively to this, and typically picked a new short-term goal to work on. The teachers also reported that when students shared that they had met their goals, they did so with a positive mood. On the other hand, when students did not meet their goals, especially when they did not act on their plans, the students were less eager to check-in.

\section{Implications for Practice}

Axiomatically, following increased student involvement in transition planning, the next step is for students to become actively involved in attaining their annual transition goals. The results of this study suggest that high school students with mild to moderate disabilities lack basic goal attainment knowledge, and the Take Action lessons can be used to increase students' knowledge. Knowledge itself is insufficient to facilitate goal attainment, however, and students need the opportunity to practice and have specific feedback on their performance and assistance in developing the 
Plan Organizer and using the Evaluate and Adjust Organizer as a tool to increase goal attainment. Action on the Plan Organizer must occur for students to attain their goal. The results from this study suggest that to increase students' use of the written Plan Organizer's components, a combination of antecedent prompts and feedback after implementing the components need to be provided, and then slowly faded as students begin to independently implement the Plan components.

\section{Authors' Note}

Jodie Martin and James Martin are not related, and just happen to have the same last name.

\section{Acknowledgment}

Special thanks to Melisa Kifer, MEd, for her contribution to this study.

\section{Declaration of Conflicting Interests}

The author(s) declaired the following potential conflict of interest with respect to the research, authorship, and/or publication of this article: Dr. James Martin is a coauthor of the Take Action lesson package used in this study. Royalty payments from the sale of Take Action go to the University of Colorado, which is the copyright owner, which limits direct benefits to James Martin.

\section{Funding}

The author(s) disclosed receipt of the following financial support for the research, authorship, and/or publication of this article: This research was supported in part by a grant from the Oklahoma Department of Rehabilitation Services.

\section{References}

Agran, M., \& Hughes, C. (2008). Asking student input: Students' opinions regarding their individualized education program involvement. Career Development and Transition for Exceptional Individuals, 31, 69-76. doi:10.1177/ 0885728808317657

Algozzine, B., Browder, D., Karvonen, M., Test, D. W., \& Wood, W. M. (2001). Effects of interventions to promote selfdetermination for individuals with disabilities. Review of Education Research, 71, 219-277.

Baer, D. M., Wolf, M. M., \& Risley, T. R. (1968). Some current dimensions of applied behavior analysis. Journal of Applied Behavior Analysis, 1, 91-97.

Balcazar, F., Keys, C. B., \& Garate-Serafini, J. (1995). Learning to recruit assistance to attain transition goals: A program for adjudicated youth with disabilities. Remedial and Special Education, 16, 237-246. doi:10.1177/ 074193259501600407

Benz, M., Yovanoff, P., \& Doren, B. (1997). School-to-work components that predict postschool success for students with and without disabilities. Exceptional Children, 63, 151-165.
Campbell, J. M. (2004). Statistical comparison of four effect sizes for single-subject designs. Behavior Modification, 28, 234-246. doi:10.1177/0145455032599264

Doren, B., Lindstrom, L., Zane, C., \& Johnson, P. (2007). The role of program and alterable personal factors in postschool employment outcomes. Career Development and Transition for Exceptional Individuals, 30, 171-183. doi:10.1177/08857 288070300030601

Field, S. (1996). Historical perspective on student involvement in the transition process: Toward a vision of selfdetermination for all students. Career Development and Transition for Exceptional Individuals, 19, 169-176. doi:10.1177/088572889601900211

Field, S., Martin, J. E., Miller, R. J., Ward, M., \& Wehmeyer, M. (1998). Self-determination for persons with disabilities: A position statement of the division on career development and transition. Career Development and Transition for Exceptional Individuals, 21, 113-128. doi:10.1177/ 088572889802100202

Finn, D., Getzel, E. E., \& McManus, S. (2008). Adapting the selfdetermined learning model for instruction of college students with disabilities. Career Development and Transition for Exceptional Individuals, 31, 85-93. doi:10.1177/0885728808318327

Gast, D. L. (2010). Single subject research methodology in behavioral sciences. New York, NY: Routledge.

German, S. L., Martin, J. E., Marshall, L. H., \& Sale, P. (2000). Promoting self-determination: Using Take Action to teach goal attainment. Career Development and Transition for Exceptional Individuals, 23, 27-38. doi:10.1177/088572880002300103

Goff, C., Martin, J. E., \& Thomas, M. K. (2007). The burden of acting White: Implications for transition. Career Development and Transition for Exceptional Individuals, 30, 134-146. doi: 10.1177/08857288070300030301

Konrad, M., Fowler, C. H., Walker,A. R., Test, D. W., \& Wood, W. M. (2007). Effects of self-determination interventions on the academic skills of students with learning disabilities. Learning Disabilities Quarterly, 30, 89-113.

Lehmann, J. P., Bassett, D. S., Sands, D. J., Spencer, K., \& Gliner, J.A. (1999). Research translated into practice for increasing student involvement in transition-related activities. Career Development and Transition for Exceptional Individuals, 22, 3-19. doi:10.1177/088572889902200102

Marshall, L. H., Martin, J. E., Maxson, L. M., Hughes, W. M., Miller, T. L., McGill, T., \& Jerman, P. A. (1999). Take action: Making goals happen. Longmont, CO: Sopris West.

Martin, J. E., \& Marshall, L. H. (1995). ChoiceMaker: A comprehensive self-determination transition program. Intervention in School and Clinic, 30, 147-156.

Martin, J. E., Marshall, L. H., \& Maxson, L. L. (1993). Transition policy: Infusing self-determination and self-advocacy into transition programs. Career Development and Transition for Exceptional Individuals, 16, 53-61.

Martin, J.E., Mithaug, D.E., Cox, P., Peterson, L. Y., Van Dycke, J.L., $\&$ Cash, M. E. (2003). Increasing self-determination: Teaching 
students to plan, work, evaluate, and adjust. Exceptional Children, 69, 431-446.

Martorell, A., Gutierrez-Recacha, P., Pereda, A., \& AyusoMateos, J. L. (2008). Identification of personal factors that determine work outcome for adults with intellectual disability. Journal of Intellectual Disability Research, 52, 1091-1101.

McConnell, A. E., Martin, J. E., Juan, C. Y., Hennessey, M. N., Terry, R. A., Kazimi, N. A., \& Willis, D. M. (in press). Identifying non-academic behaviors associated with post-school employment and education. Career Development and Transition and Transition for Exceptional Individuals.

Mithaug, D. E., Martin, J. E., \& Agran, M. (1987). Adaptability instruction: The goal of transitional programming. Exceptional Children, 56, 500-505.

Mithaug, D. K., \& Mithaug, D. E. (2003). Effects of teacherdirected versus student-directed instruction on self-management of young children with disabilities. Journal of Applied Behavior Analysis, 36, 133-136.

Taylor-Ritzler, T., Balcazar, F. E., Keys, C. B., Hayes, E., Garate-Serafini, T., \& Espino, S. R. (2001). Promoting attainment of transition-related goals among low-income ethnic minority students with disabilities. Career Development and Transition for Exceptional Individuals, 24, 147-167. doi:10.1177/088572880102400205

Test, D. W., Fowler, C. H., Richter, S. M., White, J., Mazzotti, V., Walker, A. R., \& Kotering, L. (2009). Evidence-based practices in secondary transition. Career Development and Transition for Exceptional Individuals, 32, 115-128.

Ward, M. J. (1996). Coming of age in the age of self-determination: A historical and personal perspective. In D. J. Sands \& M. L. Wehmeyer (Eds.), Self-determination across the life span: Independence and choice for people with disabilities (pp. 1-14). Baltimore, MD: Paul H. Brookes.

Watson, D. L., \& Tharp, R. G. (2007). Self-directed behavior. Pacific Grove, CA: Brooks/Cole.

Wehmeyer, M. L., Palmer, S. B., Agran, M., Mithaug, D. E., \& Martin, J. E. (2000). Promoting causal agency: The selfdetermined learning model of instruction. Exceptional Children, 66, 439-453.

Wehmeyer, M. L., \& Schwartz, M. (1997). Self-determination and positive adult outcomes: A follow-up study of youth with mental retardation or learning disabilities. Exceptional Children, 63, 245-255.

Wehmeyer, M. L., \& Schwartz, M. (1998). The self-determination focus of transition goals for students with mental retardation. Career Development and Transition for Exceptional Individuals, 21, 75-86.

Wehmeyer, M. L., \& Shogren, K. A. (2013). Self-determination: Getting students involved in leadership. In P. Wehman (Ed.), Life beyond the classroom: Transition strategies for young people with disabilities (pp. 41-68). Baltimore, MD: Paul H. Brookes. 